\title{
Cartel Stability and Economic Integration
}

\author{
Philipp J.H. Schröder*
}

August 2003

\begin{abstract}
This paper investigates the effect of economic integration on the ability of firms to maintain a collusive understanding about staying out of each other's markets. The paper distinguishes among different types of trade costs: ad valorem, unit, fixed. It is shown that for a sufficient reduction of ad valorem trade costs, a cartel supported by collusion on either quantities or prices will be weakened, thus integration is pro-competitive. If integration consists of a reductions in unit (fixed) trade costs a price setting cartel is strengthened (unaffected), while a quantity setting one is weakened.

Key Words: Collusive behavior, trade liberalisation, specific tariffs, market access cost

JEL: F15; L13; L12; F12
\end{abstract}

\section{Introduction}

Economic integration, be it regional or global, has always been accompanied by the notion that it will trigger competition and hence that it improves welfare. Such arguments have been raised in relation to European economic integration, but also in connection to closer North American economic cooperation. Examples from this vast literature are Allen et al. (1998), Emerson et al. (1992), Smith and Venables (1988) and Cox and Harris (1985), all of

\footnotetext{
*Aarhus School of Business and DIW Berlin. Address for correspondence: Aarhus School of Business, Fuglesangs Allé 4, DK-8210 Aarhus V, Denmark, Tel.: +45 894863 92, Fax: +45 894861 25, E-mail: psc@asb.dk. This paper benefited from the comments of Paul Gregory, Henrik Horn, Pascalis Raimondos-Mller, Matthew Slaughter and the participants of the 6th NOITS workshop and the 30th EARIE annual conference. The author is responsible for any remaining errors.
} 
which based their arguments both on empirical work and on rigorous formal modelling. Yet, a series of papers have questioned the general validity of the notion that integration will be pro-competitive. In particular, when taking account of the possibility of collusive behavior among firms, Davidson (1984), Fung (1992), Matschke (1999) and Lommerud and Sørgard (2001) identify situations in which economic integration may be anti-competitive in the sense that a cartel among firms from different countries becomes more stable when trade barriers are reduced. ${ }^{1}$ The fundamental reasoning behind this perspective is that reduced trade costs not only make a deviation from the (implicit or explicit) cartel more attractive, but also reduce the cost of punishment and hence make the severity of a punishment - when breaking the collusive agreement - harsher. In sum, these two effects may well increase rather than decrease the stability of the cartel.

This paper augments the literature by examining the robustness of the latter argument in relation to a differentiated modelling of trade barriers, and hence economic integration. ${ }^{2}$ In particular, a distinction among ad valorem, unit and fixed trade costs is introduced into a setting where two firms situated in two different countries have formed a cartel that prohibits exports into each other's home markets. It is shown that a clear anti-competitive effect from economic integration is confined to a reduction in unit trade costs and here it occurs for a cartel supported by collusion on prices but not for a cartel supported by collusion on quantities. Integration, consisting of reductions in ad valorem or fixed trade costs, will be pro-competitive or at least neutral independent of the mode of collusion (price- versus quantitysetting). However, there exists a region of high ad valorem trade costs where an initial cost reduction may increase the stability of a price setting cartel. Yet, a pro-competitive region will be reached for a sufficient cut in trade costs.

Most formalisations of trade costs group widely divergent items such as transport costs, tariffs, currency risks, administrative red tape or market ac-

\footnotetext{
${ }^{1}$ Davidson (1984) and Fung (1992), but also Rotemberg and Saloner (1989), examine settings where a quantity-setting cartel of foreign and home firms competes on the home market, while Matschke (1999) and Lommerud and Sørgard (2001) examine symmetric settings where there is potential interaction on both markets. Furthermore Lommerud and Sørgard (2001) contribute to the previous literature by distinguishing between cartels supported by collusion on prices or collusion on quantities. Recently Bond and Syropoulos (2003) integrate several of these aspects by examining the case of multimarket collusion and the effect on the incentives of cartel members and the impact on welfare.

${ }^{2}$ The previous literature focuses on the case of unit trade costs. In addition to a unit trade cost Matschke (1999) examines quotas and the impact from quota reductions on cartel stability. Earlier Rotemberg and Saloner (1989) examined a price setting cartel and quota regulation, in a setting with no trade costs.
} 
cess costs together under the catch-all heading (and corresponding variable) of trade costs. On the other hand, empirical work clearly distinguishes among individual items of overall trade costs, see for example Bernstein and Weinstein (2002), Baier and Bergstrand (2001), Keuschnigg and Kohler (1996), McCallum (1995), Harrigan (1993). Since different cost types affect agent and firm behavior in potentially different ways, the inclusion of a distinction between different costs in the formal modelling of economic integration appears to be an important step.

The simple distinction into ad valorem, unit and fixed trade costs used in the present paper is motivated as follows: First, ad valorem trade costs consists of items such as tariffs, insurance costs, or exchange rate risks. Second, unit trade costs could include transport costs or specific tariffs. ${ }^{3}$ Third, fixed costs are market access costs such as the cost of product certification or adjustments to local regulation, the costs of maintaining a distribution network abroad, or foreign red tape in general. The Single European Act in the late 1980s and early 1990s provides an example of a policy tackling barriers of the fixed trade cost type, whereas the early years of European integration dealt with the removal of (mostly ad valorem) tariff barriers. Similarly, the introduction of a common currency like the euro can be viewed as a reduction in ad valorem trade costs (see for example Rose (2000)). Furthermore, trade liberalisation under the governance of the WTO mainly addresses tariff cuts. Nevertheless, global trends in reduced transport costs and cross-border hauling fees must be viewed as reductions in unit trade costs.

The basic model used in the present paper is that of Lommerud and Sørgard (2001), which in turn is related to Pinto (1986). Two oligopolistic firms from two different countries have formed an implicit or explicit cartel that prohibits exports into each other's home markets and where the cartel is enforced by grim-trigger strategies. ${ }^{4}$ That means collusion is enforced by the threat that when one party deviates from the agreement, the firms revert to static noncooperative Cournot or Bertrand competition forever. Thus while the cartel exists, both firms are monopolists on their domestic market - which corresponds to maximised joint profits for the cartel. Yet, deviating from the collusive agreement reaps a one-off gain, which is counterbalanced by the subsequent punishment of reverting to the noncooperative equilibrium. Lommerud and Sørgard's (2001) central finding is that by distinguish-

\footnotetext{
${ }^{3}$ However, specific tariffs are the exception rather than the rule and almost exclusively confined to agricultural products.

${ }^{4}$ Lommerud and Sørgard (2001) also examine more advanced punishment strategies. Furthermore, see Matschke (1999) and Lommerud and Sørgard (2001), but also Fung (1992) and Bond and Syropoulos (2003), for reference to cases where such cartel structures may be relevant.
} 
ing between price-setting and quantity-setting cartels, it can be shown that an anti-competitive impact of trade costs reductions occurs for a cartel supported by collusion on prices. In this context anti-competitive means that the range of discount factors that suffice to maintain the cartel is widened, i.e. the cartel is strengthened. This finding is reproduced in the present paper for the case of unit trade costs, but not for ad valorem or fixed trade costs. Thus, the impact of economic integration on cartel stability is shown to depend also on the type of trade barrier that is tackled by the integration process.

The following section introduces the formal model. Section 3 presents the results for the different cost types. Section 4 concludes.

\section{The Model}

Consider a homogeneous good duopoly, where firms are based in separate countries, $a$ and $b$. Production is characterised by constant returns to scale and marginal costs are normalised to zero. Exporting to the respective foreign market, that is, trade between $a$ and $b$, is associated with ad valorem trade cost, $\tau$, with unit trade cost $t$, and fixed cost $f .{ }^{5}$ The following restrictions apply: $\tau<1$, to ensure a positive prices when exporting, $t<p^{M}$, where $p^{M}$ is the price of a monopolist, and $f<\pi^{M}$, where $\pi^{M}$ is the profit of a monopolist. Further joint and individual feasibility-of-trade restrictions on $\tau, t$ and $f$ are specified below. Economic integration is taken to consist of reductions in these trade costs. The demand function - identical in both markets - is

$$
q_{i}=1-p_{i} \quad ; i=a, b .
$$

In order to maximise the joint cartel profit the two firms have colluded to restrict their sales to their respective home markets. Thus in the status quo there is no trade and both firms act as monopolists on their domestic market (cartel phase). It is assumed that the cartel is supported by grim trigger strategies. If one of the firms breaks the collusive agreement by deviating and exporting into the respective foreign market (deviation phase), the cartel collapses and firms attempt to export into each other's markets. ${ }^{6}$ Thus, the

\footnotetext{
${ }^{5}$ The fixed cost $f$ is assumed to occur in each period in which trade is conducted, which appears to be the case when maintaining a distribution network or dealing with foreign red tape. If, however, fixed costs to trade are understood as a one-off event instead, then this would simply be the net present value of paying $f$ over time. What matters for our result is that these fixed costs to trade are neither associated with the price of goods nor with the quantities traded.

${ }^{6}$ Due to the existence of the trade costs, home markets are somewhat sheltered such
} 
static noncooperative Nash outcome will be the resulting equilibrium for all subsequent periods (punishment phase).

Profit expressions $\pi^{j k}$ are derived, where $j$ denotes the mode of competition, and $k$ denotes the different phases. The possible modes of competition are competition on prices, $B$, or competition on quantities, $C$. The different phases are $M$ for the cartel phase, i.e. both firms act as monopolists, $D$ for the deviation phase, i.e. the profits of the attacking firm, and $P$ for the punishment phase, i.e. profits when the duopoly is in the noncooperative equilibrium. It turns out to be useful to calculate profits when both ad valorem trade costs, $\tau$, and unit trade costs, $t$, are present at the same time, while the case of fixed trade costs $f$ is treated separately below.

$$
\begin{aligned}
\pi^{C M} & =\pi^{B M}=\frac{1}{4}, \\
\pi^{C D} & =\frac{1}{4}+\frac{(1-\tau-2 t)^{2}}{16(1-\tau)}, \\
\pi^{B D} & =\frac{1}{4}+\frac{1-\tau-2 t}{4}, \\
\pi^{C P} & =\left(\frac{1-\tau+t}{3(1-\tau)}\right)^{2}+\frac{1}{1-\tau}\left(\frac{1-\tau-2 t}{3}\right)^{2}, \\
\pi^{B P} & =\frac{t-\tau t-t^{2}}{(1-\tau)^{2}} .
\end{aligned}
$$

While the cartel is maintained (2), each firm acts as a monopolist on its domestic market, charging the profit maximising price $\frac{1}{2}$ and realising a quantity $\frac{1}{2}$, which yields profits of $\frac{1}{4}$.

An attack on the foreign firm by deviating from the collusive agreement and exporting to the foreign market is in the first instance not counteracted, i.e. the attacked firm is sluggish in adjusting quantities and prices on its home market and unable to immediately launch exports in retaliation. Thus the deviating firm still harvests profits of $\frac{1}{4}$ on its home market. When the firms are quantity-setters, the foreign firm persists during the attack in its quantity $\frac{1}{2}$. Thus the attacking firm faces a demand curve $q=\frac{1}{2}-p$, which determines the optimal export quantity $q^{x}=\frac{1}{4}-\frac{t}{2(1-\tau)}$. Accordingly, the price on the foreign market becomes $p=\frac{1}{4}+\frac{t}{2(1-\tau)}$ and profits for the deviating firm, after taking account of the trade costs, become $\pi^{C D}=\frac{1}{4}+(1-\tau) p q^{x}-t q^{x}$, which simplifies to the expression in (3).

that under Bertrand competition, the home firm, though disciplined by the threat of imports, still services the home market alone; no actual trade takes place after the cartel has collapsed. 
When firms are price-setters instead, the deviating firm again harvests profits of $\frac{1}{4}$ on its home market. In addition, on the foreign market the attacker can capture total sales by marginally under-pricing the other firm. Yet, the trade costs of exporting the quantity $\frac{1}{2}$ at a price of $\frac{1}{2}$ reduce the actual profits obtained as is shown in (4). Also, from (3) and (4) it follows that the joint restriction $1>\tau+2 t$ must hold for the ad valorem and unit trade costs. This condition ensures that an attack is feasible, i.e. that trade is profitable in the deviation phase. ${ }^{7}$

In the punishment phase, i.e. when firms have reverted to the static noncooperative equilibrium forever, both firms (attempt to) export. When firms are competing in quantities, exports do take place. The price is determined by the sum of domestic and imported quantities. Firms maximise profits by selling the quantity $\frac{1+\frac{t}{1-\tau}}{3}$ on the domestic market, while exporting the quantity $\frac{1-2 \frac{t}{1-\tau}}{3}$. These quantities result in price level $\frac{1}{3}+\frac{t}{3(1-\tau)}$ in both countries, and single period profits are as stated in (5).

When firms are price-setters, the punishment phase does not feature any realised exports. However, the threat of foreign exports after the cartel has collapsed, i.e. attempted exports, forces domestic firms to price marginally below the lowest possible import price associated with non-negative profits for the foreign firm. The foreign firm's profits from exporting are $(1-\tau) p(1-$ $p)-t(1-p)$, setting this expression equal to zero and solving for $p$ determines the price associated with zero export profits as $\frac{t}{1-\tau}$, which in turn is the highest possible price the domestic firm can charge on the home market while still avoiding any imports. The resulting profits are as stated in (6).

Parallel to the above, the case of fixed trade costs $f$ can be examined. Denoting profits when there are only fixed costs to trade by $\hat{\pi}^{j k}$, one can state:

$$
\begin{aligned}
\hat{\pi}^{C M} & =\hat{\pi}^{B M}=\frac{1}{4}, \\
\hat{\pi}^{C D} & =\frac{1}{4}+\frac{1}{16}-f, \\
\hat{\pi}^{B D} & =\frac{1}{4}+\frac{1}{4}-f, \\
\hat{\pi}^{C P} & =\frac{2}{9}-f, \\
\hat{\pi}^{B P} & =f .
\end{aligned}
$$

\footnotetext{
${ }^{7}$ If the condition $1>\tau+2 t$ is not fulfilled, the two countries are in fact insulated from competition, such that there is no need to form a cartel in the first place.
} 
The profits while the cartel persists are, as before, the profits of a monopolist (7). Deviating from the collusive agreement does, under the presence of a fixed trade cost, result in profits (8) and (9). In the Cournot case, the attacker maximises its profits given that the attacked firm persists in its quantity $\frac{1}{2}$, while in the Bertrand case, the attacker can capture the entire foreign market by marginally under-pricing the foreign firm. In both instances, the attacker encounters the fixed costs of exporting $f$. Also from (8) it follows that $f<\frac{1}{16}$ must hold in order for an attack - and thus trade - to be feasible.

After the collapse of the cartel (punishment phase), given that firms compete on quantities, both firms set quantities $\frac{1}{3}$ on the home and foreign market respectively, the resulting price which is identical on both markets is $\frac{1}{3}$. However, in order to conduct the exports, there is still the fixed trade cost $f$.

When firms are competing on prices instead, actual exports do not materialise. Instead, the domestic firm sets it price at a level associated with zero profits for imported goods, so as to avoid any import activity. The profits from export activity are $p(1-p)-f$, which after setting the expression equal to zero defines the price on both markets in the punishment phase $\frac{1}{2}-\frac{\sqrt{1-4 f}}{2}$ and accordingly the quantity $\frac{1}{2}+\frac{\sqrt{1-4 f}}{2}$ sold by each firm on its respective home market. Calculating the profits results in the intuitively obvious conclusion that the profits that are possible are exactly the value of the fixed costs to exports (11), i.e., if the home firm made any profits above $f$, this would immediately trigger export activity of the foreign firm.

\section{Results}

Cartel stability in this setting is an evaluation of situations where the initial collusive agreement becomes easier or more difficult to maintain. Formally, one investigates the range of the common discount factor $\delta$ for which collusion will remain unchallenged. Since in all settings calculated above the profit for a cartel member, i.e. the monopolists profit, is less than the profit from deviation, but larger than profits in the punishment phase, there must exist some $\delta^{*}$ such that for $\delta<\delta^{*}$ the threat of the punishment phase becomes so small, that a member of the cartel will abandon the collusive agreement in favor of the short term gains in the deviation phase. Hence, an investigation of cartel stability must examine how $\delta^{*}$ reacts to changes in the various trade costs. In particular, widening the range of $\delta$ where collusion is supported, i.e. a reduction of $\delta^{*}$, implies that the cartel is strengthened. Conversely, widening the range of $\delta$ where the collusive agreement will be challenged by 
deviation, i.e. increasing $\delta^{*}$, implies that the cartel is weakened.

Both firms will support collusion, i.e. the cartel is sustained, if

$$
\frac{1}{1-\delta} \pi^{M} \geq \pi^{D}+\frac{\delta}{1-\delta} \pi^{P}
$$

is fulfilled. Solving (12) with equality after inserting the values from the above profit expressions determines $\delta^{*}$.

\section{Ad valorem trade costs}

Plugging (2), (3) and (5) into (12) the critical $\delta_{\tau t}^{* C}$ for the case of Cournot competition and the presence of ad valorem and unit trade costs turns out to be

$$
\delta_{\tau t}^{* C}=\frac{9(1-\tau)(1-2 t-\tau)}{13+22 t-6 \tau-14 t \tau-7 \tau^{2}}
$$

How does a change in ad valorem trade cost $\tau$ affect $\delta_{\tau t}^{* C}$, i.e. the lowest discount factor for which the collusive agreement is still sustainable? Differentiating (13) with respect to $\tau$ gives

$$
\frac{\partial \delta_{\tau t}^{* C}}{\partial \tau}=-3 \frac{12\left(5(1-\tau)^{2}+4 t(1-\tau)-4 t^{2}\right)}{\left(13+22 t-6 \tau-14 t \tau-7 \tau^{2}\right)^{2}}<0,
$$

which is always negative since $4 t(1-\tau)>4 t^{2}$ due to the trade feasibility condition $1>\tau+2 t$. Thus as $\tau$ decreases, $\delta_{\tau t}^{* C}$ increases, implying that the range of $\delta$ where collusion is sustainable is reduced. Or put differently, economic integration that consists of a reduction in ad valorem trade costs reduces the stability of a cartel supported by collusion on quantities, i.e. integration is pro-competitive.

The case of Bertrand competition is obtained when plugging (2), (4) and (6) into (12). The critical $\delta_{\tau t}^{* B}$ becomes

$$
\delta_{\tau t}^{* B}=\frac{(1-\tau)^{2}}{2-2 t-3 \tau+\tau^{2}}
$$

Differentiating (15) with respect to $\tau$ gives

$$
\frac{\partial \delta_{\tau t}^{* B}}{\partial \tau}=-\frac{(1-\tau)(1-4 t-\tau)}{\left(2-2 t-3 \tau+\tau^{2}\right)^{2}},
$$

which is negative, i.e. economic integration consisting of a reduction in ad valorem trade costs is pro-competitive, as long as $\tau<1-4 t$. Combination with the trade feasibility condition yields the following condition for the 
converse case. A reduction in ad valorem trade costs decreases $\delta_{\tau t}^{* B}$, i.e. the range of $\delta$ where the collusion is sustained increases, when $1-4 t<$ $\tau<1-2 t$. So in principle both the case of a pro-competitive effect and the case of an anti-competitive effect of ad valorem trade cost reductions under Bertrand competition is possible. However, since economic integration implies reductions in trade costs, the pro-competitive region will eventually be reached for a sufficient reduction in $\tau$. On the other hand, a $t>\frac{1}{4}$ implies that the range of pro-competitive $\tau$ levels is empty.

\section{Unit trade costs}

Since both ad valorem and unit trade costs are present in (13) and (15), these critical values for $\delta$ can be used directly to examine the case of unit trade costs. $^{8}$

When firms are competing in quantities, how does a change in unit trade cost $t$ alter $\delta_{\tau t}^{* C}$ ? Differentiating (13) with respect to $t$ gives

$$
\frac{\partial \delta_{\tau t}^{* C}}{\partial t}=-3\left(\frac{12(1-\tau)}{13+22 t-6 \tau-14 t \tau-7 \tau^{2}}\right)^{2}<0
$$

which is always negative. Namely, the lowest discount factor for which the collusive agreement under Cournot competition is still sustainable increases when unit trade costs are reduced. Thus economic integration is pro-competitive.

When firms compete on prices the situation changes. Differentiating (15) with respect to $t$ yields

$$
\frac{\partial \delta_{\tau t}^{* B}}{\partial t}=\frac{2(1-\tau)^{2}}{\left(2-2 t-3 \tau+\tau^{2}\right)^{2}}>0
$$

which is always positive. Hence, an increase in $t$ increases $\delta_{\tau t}^{* B}$, implying that the range of parameters where the collusion is sustainable shrinks, i.e. the cartel is weakened. Accordingly, economic integration which consists of a reduction in unit trade costs does strengthen a cartel operating under Bertrand competition, i.e. integration is anti-competitive.

\section{Fixed costs to trade}

Finally, consider the effect of reductions in fixed costs on cartel stability. Plugging (7), (8) and (10) into (12) the critical $\delta_{f}^{* C}$ for the case of Cournot competition and the presence of fixed costs to trade is calculated to be

\footnotetext{
${ }^{8}$ Results for the unit trade costs case turn out to be (and should be) parallel to the findings in Lommerud and Sørgard (2001).
} 


$$
\delta_{f}^{* C}=\frac{9}{13}(1-16 f)
$$

Differentiating (19) with respect to $f$ gives, $-\frac{144}{13}$, which shows that the lowest discount factor for which the collusive agreement is sustainable increases with a reduction in $f$, hence the cartel is weakened.

For Bertrand competition the critical $\delta$ is obtained when plugging (7), (9) and (11) into (12); it turns out to be identical to the textbook (zero transport costs) case of Bertrand collusion:

$$
\delta_{f}^{* B}=\frac{1}{2}
$$

The intuitive conclusion is, that the increased profitability from a cut in fixed trade costs $f$ by amount $y$ not only enters directly with value $y$ into the profit of the attacking firm, but also enters the profits in the punishment phase with value $-y$. Thus the effect is neutralized, and we return to the threshold value of sustainability of collusion $\frac{1}{2}$. This implies that under price competition, economic integration that reduces fixed trade costs has a neutral effect on cartel stability.

\section{Some intuition}

Among the various results from above we will elaborate on two: first, the opposing impact of a unit trade cost reduction under Cournot and Bertrand competition; and, second, the opposing effects of ad valorem versus unit trade cost reductions.

Concerning the first point, an anti-competitive effect of unit trade cost reductions under Bertrand competition but a pro-competitive effect under Cournot competition, i.e. the finding of Lommerud and Sørgard (2001), the following intuition applies. What happens in the case of a unit trade cost reduction under Bertrand competition is that even though a reduction in $t$ makes a deviation from the collusive agreement more attractive, it also increases the severity of the punishment. In sum, the punishment effect dominates. Under Bertrand competition in the punishment phase the trade costs are the only market protection left for the home firm after the cartel is abandoned, while under Cournot competition in the punishment phase, the strategic interaction ensures that even though reduced trade costs cause losses on the home market, they create profit gains on the foreign market since both firms service both markets.

Consider now the finding that effects from unit and ad valorem trade cost reductions differ. In particular, under Bertrand competition a sufficient 
ad valorem trade cost reduction is pro-competitive, while any unit trade cost reduction is anti-competitive (see (16) and (18)). A crucial difference between these two cases is in the profits during the punishment phase as given in (6). Differentiating with respect to $t$ and $\tau$ gives $\frac{\partial \pi^{B P}}{\partial t}=\frac{1-2 t \tau}{(1-\tau)^{2}}$ and $\frac{\partial \pi^{B P}}{\partial \tau}=$ $\frac{t}{1-\tau} \frac{1-2 t \tau}{(1-\tau)^{2}}$ respectively. Both expressions are positive, hence a cut in trade cost reduces profits in the punishment phase. However since $t<1-\tau$ holds, profits in the punishment phase react less severely to reductions in ad valorem trade costs than to reductions in unit trade costs. More intuitively, there are two fundamental forces at work: (i) in all scenarios prices in the deviation phase are high, while prices in the punishment phase are low; (ii) trade cost reductions increase the deviation price from the firms perspective but reduce the price it can maintain during the punishment phase. A unit trade costs reduction - even though it means a price rise in the deviation phase - has a severe cost in the punishment phase, were the trade cost is the only protection available to the firms under Bertrand competition. On the other hand, an ad valorem trade cost reduction adds much to the payoff in the deviation phase, where prices are high, while it costs relatively little in the punishment phase were - since prices are depressed anyway - a further ad valorem reduction makes little difference. This "softer" effect on the punishment prices and profits cushions the threat from export retaliation such that with ad valorem trade cost reductions the profit gain in the deviation phase can be attractive enough to trigger an attack on the cartel.

Table 1: A reduction in trade costs is ...

\begin{tabular}{lll}
\hline & Cournot & Bertrand \\
\hline ad valorem & pro-competitive & pro-(anti-)competitive \\
unit & pro-competitive & anti-competitive \\
fixed & pro-competitive & neutral \\
\hline
\end{tabular}

Table 1 summarizes the results of the paper. Previous literature - e.g. Davidson (1984), Fung (1992) - has established various versions of anticompetitive effects, yet always focusing on the case of unit trade costs. The work by Lommerud and Sørgard (2001) has extended the discussion by emphasising the role of the mode of competition (Cournot versus Bertrand), yet still only examining the case of unit trade costs. The present paper then, contributes by examining the issue of cartel stability and economic integration for different forms of trade costs and thus different forms of economic integration. It is found that clear anti-competitive effects from integration are in fact less relevant or even non-existent for the case of ad valorem and unit trade costs. However, what the real world relevance of these three classes 
of trade costs is, and more importantly what type of trade costs actual integration policies tackle, remains a question for empirical work.

\section{Conclusion}

The paper investigates the effect of economic integration on the ability of an international duopoly to maintain a cartel that prohibits exports into each other's markets. Such a cartel can ensure monopolistic profits for the participating firms, but is under a constant threat of deviation. However, the temptation to break the cartel is counterbalanced by the threat of reverting to the non-cooperative equilibrium with open competition on both markets. Since reductions in trade barriers make deviation more attractive, but can increase the severity of a punishment at the same time, there may exist situations in which integration has an anti-competitive effect. This type of effect has, for example, been presented by Davidson (1984), Fung (1992) and Lommerud and Sørgard (2001), and has been taken to constitute counterexamples to the popular notion that integration will promote competition.

Based on the framework of Lommerud and Sørgard (2001) we examined the anti-competitive effect from integration in relation to different forms of trade costs and hence different forms of economic integration. Within this framework, sufficient reductions in ad valorem trade costs, such as tariffs or exchange rate risks, reduce cartel stability. Thus integration polices such as forming a customs union, implementing WTO regulations or a common currency - i.e. strategies that mainly tackle trade costs of the ad valorem type - are pro-competitive. Reductions in fixed market access costs, such as costs associated with product certification or the costs of maintaining a distribution network abroad have also a weakening or neutral effect on cartel stability. Thus integration policies such as the Single European Act will at best be pro-competitive and at worst be neutral. Finally, reduction in unit trade costs, such as transport costs, will strengthen cartel stability if firms are price-setters, and weaken the cartel if firms are quantity-setters. Thus only policies that tackle unit cost trade barriers are potentially anti-competitive. To sum up, this paper has shown that a conclusion as to whether economic integration is pro- or anti-competitive must also distinguish the type of trade barriers that are tackled. 


\section{References}

Allen, C.; M. Gasiorek and A. Smith (1998), The Competition Effects of the Single Market in Europe, Economic Policy, Vol.13, pp.441-486.

Baier, S.L. and J.H. Bergstrand (2001), The Growth of World Trade: Tariffs, Transport Costs, and Income Similarity, Journal of International Economics, Vol. 53 (1), pp.1-27.

Bernstein, J.R. and D.E. Weinstein (2002), Do Endowments Predict the Location of Production? Evidence from National and International Data, Journal of International Economics, Vol.56 (1), pp.55-76.

Bond, E.W. and C. Syropoulos (2003), Is the Tariff the 'Mother of Trust'? Reciprocal Trade Liberalization with Multimarket Collusion, Version Presented at Conference on Competition, Contracts and International Trade, University of Kiel, Germany, May 2003.

Cox, D and R. Harris (1985), Trade Liberalisation and Industrial Organisation: Some Estimates for Canada, Journal of Political Economy, Vol.93, pp.115-145.

Davidson, C. (1984), Cartel Stability and Tariff Policy, Journal of International Economics, Vol. 17, pp.219-237.

Emerson, M.; M. Aujean, M. Catinat, P. Goybet and A. Jacquemin (1988), The Economics of 1992, Oxford University Press.

Fung, K.C. (1992), Economic Integration as Competitive Discipline, International Economic Review, Vol.33 (4), pp.837-847.

Harrigan, J. (1993), OECD Imports and Trade Barriers in 1983, Journal of International Economics, Vol.35, pp.91-111.

Keuschnigg, C. and W. Kohler (1996), Austria in the European Union: Dynamic Gains from Integration and Distributional Implications, Economic Policy, April 1996, Issue 22, pp.155-190.

Lommerud, K.E. and L. Sørgard (2001), Trade Liberalisation and Cartel Stability, Review of International Economics, Vol.9(2), pp.343-355.

Matschke, X. (1999), On the Impact of Import Quotas on a Quantity-fixing Cartel in a two-country setting, Jahrbücher für Nationalökonomie und Statistik, Vol.219 (3-4), pp.438-457.

McCallum, J. (1996), National Borders Matter: Canada-U.S. Regional Trade Patterns, American Economic Review, Vol.85 (3), pp.615-23.

Pinto B.R. (1986), Repeated Games and the 'Reciprocal Dumping' Model of Trade, Journal of International economics, Vol.20, pp.357-366.

Rose, A. (2000), One Money, One Market: The Effect of Common Currencies 
on Trade, Economic Policy, Vol. 15, Issue 30, pp.7-33.

Rotemberg, J.J. and G. Saloner (1989), Tariffs versus Quotas with implicit Collusion, Canadian Journal of Economics, Vol.22, pp.237-244.

Smith, Alasdair and A.J. Venables (1988), Completing the Internal Market in the European Community: Some Industry Simulations, European Economic Review, Vol. 32, pp.1501-1525. 